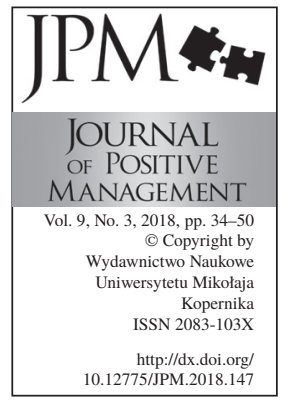

\section{GLOBAL CONTAINER SHIPPING OPERATORS' STRATEGIES AND THEIR IMPACT ON LOGISTICS SUPPLY CHAINS} Andrzej Grzelakowski

\author{
Gdynia Maritime University, Gdynia, Poland \\ e-mail: a.grzelakowski@wpit.umg.edu.pl
}

\begin{abstract}
The world economic and financial crisis that seriously hit the global economy and especially its trade and transport sectors in the years 2008-2009 also affected with significant force the global maritime container transport. This strategic maritime transport subsector is regarded as a driving force of smooth development of the global logistics supply chains and the backbone accelerating globalization processes. However, since 2010 effective demand and potential supply on the global container freight market are in constant state of disequilibrium, caused to a large extend by wrong tonnage investment strategies of container operators. Lack of ability to adapt the supply side to changes occurring on the demand side of the container market has brought numerous serious financial and economic consequences which not only affected the global container shipping operators but also hit other parties involved in the logistics supply chains spread within the global logistics space created in the contemporary global economy.
\end{abstract}

Purpose: The main objective of this paper is to evaluate the dynamics of global maritime container market, especially its demand side which fluctuates vigorously, and assess the short and medium term strategies applied by the powerful shipping operators in terms of their multi-channel impact on the other parties of the global intermodal supply chain and the global logistics system as a whole.

Methodology: The traditional method of maritime freight analysis was applied based on container freight and charter indices, such as SCFI or HFI. They reflect the amplitude of freight rate per TEU fluctuations in a certain period of time (e.g. quarter, week, etc.) which is congruent with the effective demand changes confronted with the existing potential supply. Growth of tonnage capacity, determined by the global container shipping operators' strategies aimed for further development and better utilization of the existing transport potential of container fleet acting on the very competitive global freight market, has been assessed in terms of logistics efficiency and its effects have been estimated within the global value chain.

Findings: The obtained results indicate that: 1/ global maritime container transport market is still significantly unbalanced and subject to high dynamics of demand fluctuations, and consequently freight rates, 2/ applied strategies of maritime global container operators in the operational and investment area fail to bring intended results, leading to strong capital horizontal integration in the sector of maritime container transport and vertical integration within the global logistic supply chains, 3 / the situation destabilizes the operations of global supply chains and consequently the global TSL sector, preventing forwarders and shippers from taking rational decisions on a medium and short term basis, 4/ this relatively long-standing situation (from 2010) shakes the foundations of 
transport and logistics order worldwide, 5 / the beneficiary of this situation on the market of maritime container transport and strategic decisions of global container operators is global economy as well as consumers of goods imported by sea in containers.

Originality/value: The approach proposed by the author regarding the analysis of the effectiveness of freight market operations in the context of developed and implemented operational and investment strategies of maritime container operators with an attempt to assess the effects of such decisions within global logistic supply chains has not been the subject of research until now. The obtained initial results which require further detailed analysis, provide significant values, both theoretical (enrich the market theory) and practical (as regards taking rational decisions and effective management of global supply chain).

Keywords: global container shipping, container shipping operators, container freight market, container operators' strategies, global logistics supply chain

Paper type: Research paper/conceptual paper
GLOBAL CONTAINER SHIPPING

Andrzej Grzelakowski

\section{Introduction - maritime transport and role in the global economy}

The contemporarily established model of global economy is based on the development of quality-wise new, crucially important forms of economic relations with supply chains and networks. Global supply chains and networks integrate economically and spatially the centres of supply, production, distribution and consumption within the global economy. It is happening through the integration and optimization of all functions, processes and tasks performed by particular components of the established vertical structures, i.e. purchase, transport, warehousing, production, distribution, marketing, finances, returns, and the like. Therefore, the global supply networks and chains based on the logistics provide grounds for a new organization of business activity, integrated entity-wise, functionally and spatially, conducted on a global scale, including international trade and transport. At the same time, they rationalize the implementation of economic processes, per costs and time, facilitating and supporting the economic development (Mangan et al., 2009).

Among numerous factors affecting the development of global supply chains and networks, transport is crucially important since it determines the conditions, forms and effectiveness of broadly understood physical processes regarding the transfer of goods, i.e. carriage, handling, inventory, warehousing, etc. Within particular components of the global logistic supply chains, they may constitute as much as $70-80 \%$ of all processes and related activities, making significant contribution in creating the value chain, generated by this type of structure (Pryke (Ed.), 2009). Therefore, this factor is perceived as particularly important in order to ensure efficient and effective implementation of economic processes not only for flexible operations and development of global supply chains but also for global economy at different stages of business cycle development (Chopra and Meindl, 2010; Branch, 2009). At present, a significant role in this respect is attached to 
GLOBAL CONTAINER SHIPPING

Andrzej Grzelakowski

the maritime transport, and especially its key segment, namely seaborne container transport.

Maritime transport carries over 10.8 bn tonnes of cargo (2017), i.e. over $81 \%$ of the world trade volume (UNCTAD, 2018). It is predicted that between 2018 and 2023, the average annual rate of growth of seaborne transport would amount to $3.8 \%$. If this high rate of growth is sustained, then in 2020 this transport will increase to $12.5-13.0$ bn tonnes, and in 2030 it might exceed 16.5 bn tonnes (WSC, 2018; Mandryk, 2011). Whereas, per transport performance unit, the share of maritime transport in the global trade services amounts to more than $92 \%$ and is steadily increasing because of the growing volume and average distance of carriage.

Maritime transport is also a dominant sector of transport in the global trade, if its share is measured by the quantity of goods carried per value units. Excluding the EU internal trade, it is estimated that nowadays its share in overall transport amounts to ca. 76 per cent. Whereas, including the trade within EU member states, as an integral part of global trade, it is estimated that at present the share of maritime transport in the world trade services based on export value totals 59 per cent (Grzelakowski, 2018).

Assuming, under WTO data from 2018, that the value of global freight export in 2017 amounted to USD 17.73 bn, we can estimate that the value of maritime trade on a global scale reaching nearly USD $11.0 \mathrm{bn}$. (WTO, 2018). The value of seaborne transport, as defined above, has steadily been increasing - faster than the volume of exported goods. As a result, it is assumed that in 2023, maritime transport will carry goods worth at least USD $13.1 \mathrm{bn}$. \$. Consequently, it means that today the average value of one ton of seaborne cargo totals over USD 1,050 and within the last decade the tendency has steadily been increasing (however, between 2014 and 2016, we observed a significant decrease in this area).

Apart from the increase in prices and changes in the assortment structure of global trade and transportation, this tendency is significantly affected by the process of bulk-breaking and, first of all, containerization. Since the tendency is increasing, which refers to the development of logistic supply chains and networks demanding more rapid increase in the pace, timeliness and safety of supplies, the percentage of high-value goods in maritime trade is steadily increasing; nowadays, their share in global trade is estimated at min. 71 per cent of the value of global export, i.e. min. USD 12.7 bn. (UNCTAD, 2018) Assuming under the UNCTAD and WTO database that at present 17.1 per cent of the maritime transport volume and as much as 58 per cent of its value is transported in containers on a global scale, it is estimated that in 2017 this mode of transport carried goods worth USD 6.38 bn in more than 148 million TEU (ICS, 2018). The value can also be expressed with reference to the value of global production - its share totals USD 1 per each USD 15 of generated production (Global Insight, 2016). It means that the average value 
of 1 ton of seaborne cargo exported in containers amounts to ca. USD 4,100 and is 4.1 times higher than the average unit value of cargo in maritime trade (ICS, 2018). Therefore, maritime transport ensures and creates, in the technical and operational as well as economic and financial terms, adequate transport and logistics potential indispensable for further undisturbed development of global trade, and consequently the increase in global economy. Intermodal transport plays a vital role in this respect - containerization as the carrier of globalization and leverage of global trade development as well as efficiency in the logistic supply chains operations. It results from that fact that nowadays the average costs of container carriage by sea constitute only 3-4 per cent of the value of cargo carried by this type of transport and the cost of carrying 40" container with cargo at a distance of 1 nautical mile totals on average USD 0.10 , which constitutes barely a fraction of costs of its carriage by road. As a result, on a global scale, the share of global import transport handling costs has been decreasing for over 20 years. Thus, between 2005 and 2017, the global trade volume was increasing on average by 3.8 per cent annually, and its value by $7.9-8.1$ per cent, whereas the shippers' expenditure measured as per freight paid, was increasing on average only within 50 per cent of this value. The value of expenditure incurred by exporters and importers with regard to freight paid for the carriage of goods by sea is estimated nowadays at ca. USD 798 bn, which constitutes ca. 4.5 per cent of the global import in total and 6.7 per cent of the value of maritime transport goods determined per import (Alphaliner, 2018).

\section{Uncertainty and risk in the global container transport sector and their impact on freight markets and logistics supply chains}

Maritime transport, and in particular its container transport sector, belongs to these types of business activity which operate under permanent uncertainty and risk. There are many reasons for this; internal reasons which include e.g. the nature of environment where the transport is performed, and external ones, including, first of all, regulatory and organizational market conditions. However, primarily the aspect of uncertainty and risk related to business activity in maritime shipping results from (Grzelakowski, 2018):

- significant internationalization of the supply side of global freight container markets, featuring very advanced process of separating the issue of ownership and control of the fleet by the flag states from the issue of fleet registration (formal affiliation) and unification of the regulatory mechanism of this shipping sector,

- increasing concentration of capital and production in the sector of maritime transport, which is reflected not only in establishing cartels and consortia, but also vertical forms of capital as well as organization and trade relations within the global logistic supply chains (see Figure 1), 
MERGERS AND ACQUISITIONS

Their share has increased further with

the completion of the operational integration

of the new mergers in 2018.

January 2018

Top 15 carriers

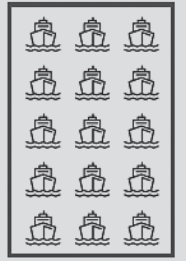

June 2018

Top 10 carriers

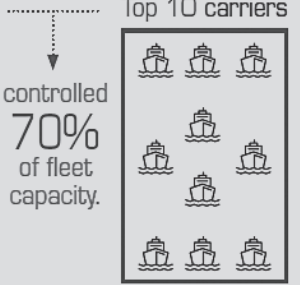

\section{ALLIANCES}

Alliances reorganized

to form three larger

alliances of global

carriers in 2017:

2M, the Ocean Alliance

and "The" Alliance,

accounting for $93 \%$

of East-West lanes.

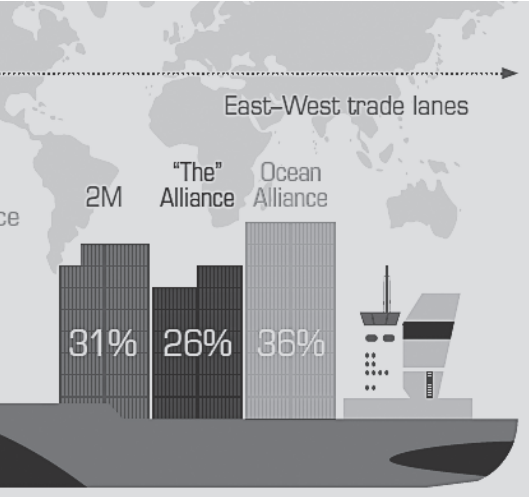

Figure 1. Existing level of integration and concentration of the global container market supply side Source: UNCTAD, 2018 .
- strong competitive pressure originating from significant openness and flexibility of freight market operations on a global scale - freedom to enter and leave the market, significant facilities regarding acquisition and transfer of tonnage (charter, leasing, etc.); at the same time we can observe constant pressure on the reduction of tonnage operating costs (rationalization), which, with relatively high capital intensity of business activity in container shipping, high share of fixed costs in the total ship handling costs and significant variability of income from the sale of basic operation services, poses a risk of financial crisis for the shipping operators,

- need to provide prompt technical and organizational adjustments to the increasing systemic and international requirements regarding: safety of shipping (requirements of IMO convention and guidelines), ecological safety (sulphur directive, reduction of $\mathrm{CO} 2$ emission), as well as social safety (ILO, ITF) and supply chain security (SCS), including protection of data against cyberattack, (ICS, 2018, ICS, 2014)

- lack of political and economic stability within the currently existing model of global economy, which is reflected e.g. in: military conflicts, increasing protectionism, high threat of terrorism and piracy, etc.

The element of uncertainty and risk related to business activity conducted in the container maritime transport makes freight markets, where container operators render their services, very dynamic (see Figure 2). Such kind of dynamics can be observed in significant fluctuations of the volume and structure of effective and potential demand and potential supply.

The fluctuations can be observed in short, medium and long time periods. The amplitude of these fluctuations in various time periods is diversified. The phenomenon and its scale is presented in Figure 3. In general, without going into the specifics of reasons and circumstances of the variability of business activity intensity in the global container maritime transport, we can indicate that 


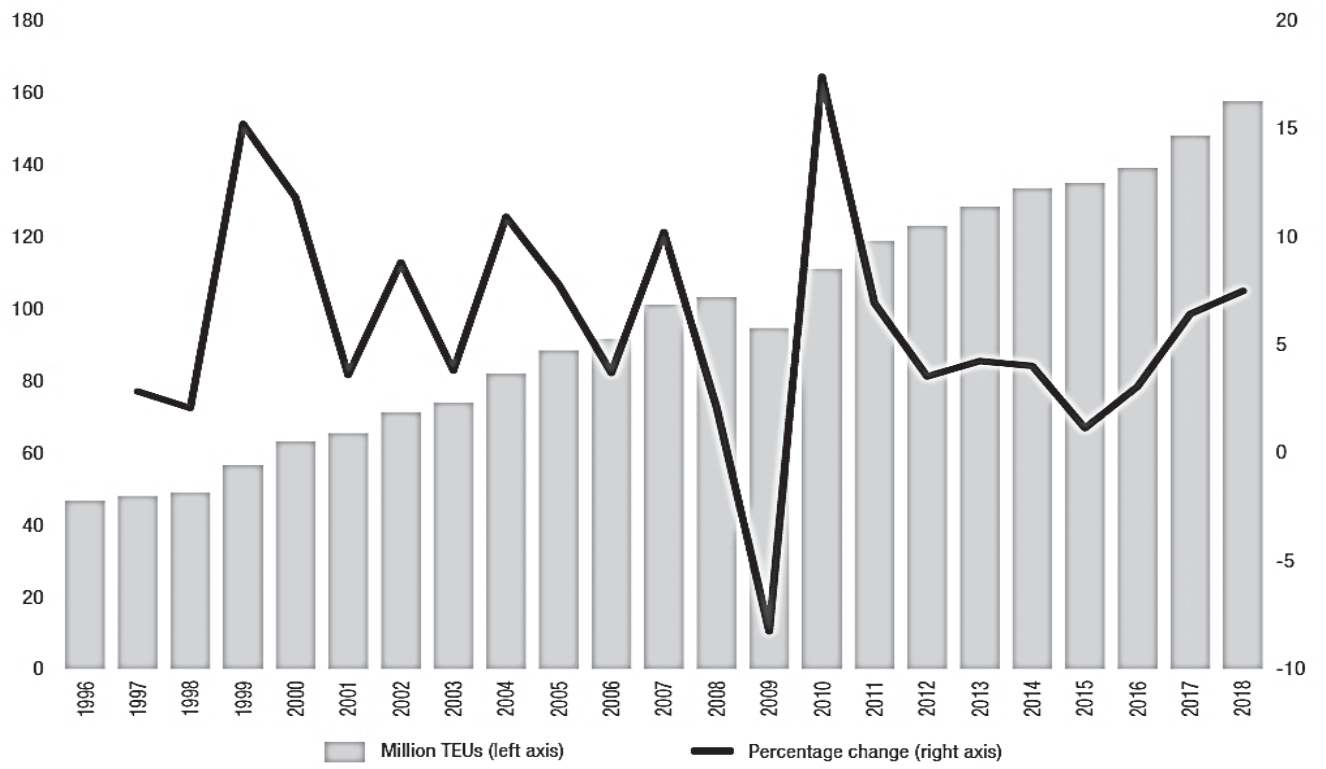

$\Delta$ Figure 2. The market of global maritime container - its development and dynamics in the years 1996-2018. Million 20-foot equivalent units and percentage annual change

Source: UNCTAD, 2018; MDS, 2018. $\boldsymbol{\nabla}$ Figure 3. Demand and supply dynamics of the global container market in the years 2007-2017

Source: UNCTAD, 2018; Clarkson Research, 2017, 2018 [1].

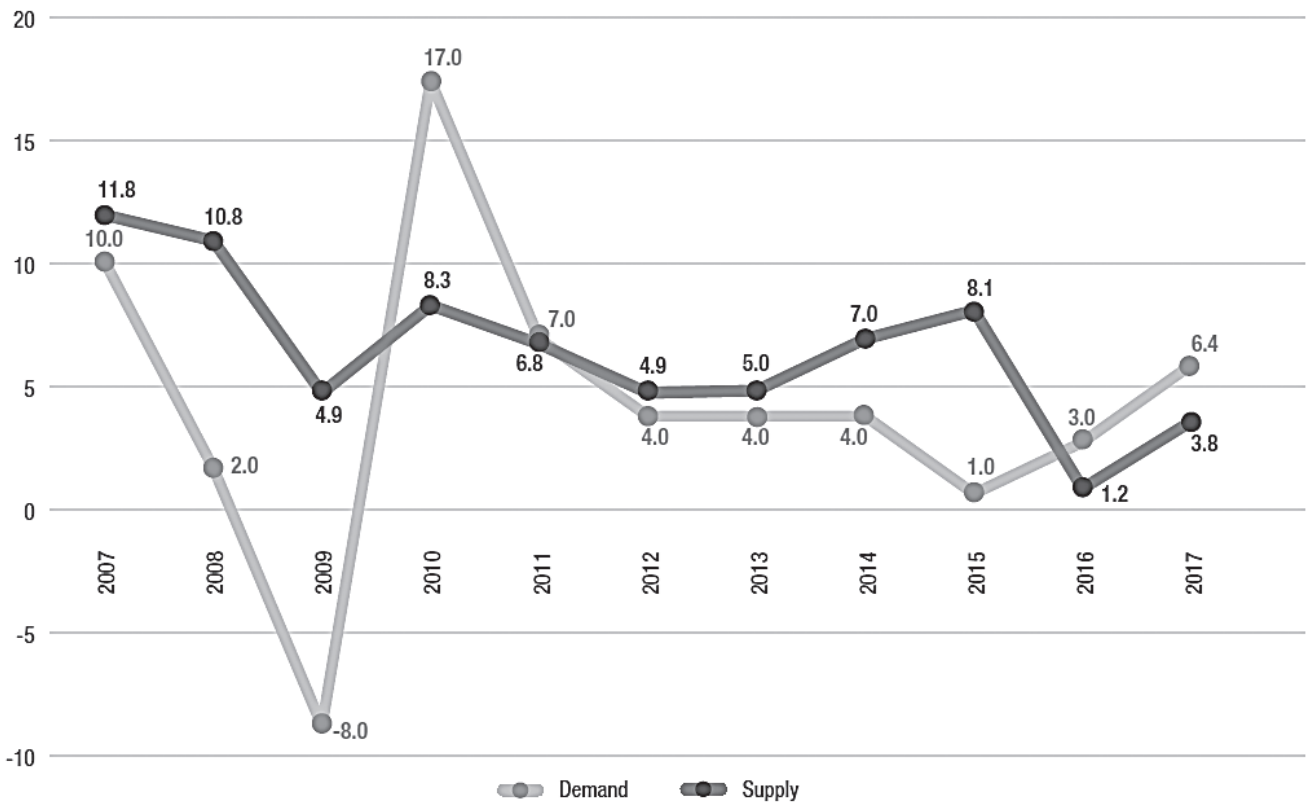


GLOBAL CONTAINER SHIPPING

Andrzej Grzelakowski

nowadays apart from the reasons resulting from the nature of freight market, which operates like the system of mass random services regarding the demand and supply, the main reason for its dynamics (apart from random events - accidental or occasional), involves various recurrent fluctuations (Grzelakowski, 2012).

We can differentiate the three main types with particular types of fluctuations. They include:

- seasonal cycles related to the seasonality of production, consumption or distribution noticeable in the system of global logistic maritime and land supply chain,

- business cycles, including, first of all, short-term inventory cycle (Kitchin), short-term investment cycle (Juglar) and long-term Kuznetz and Kondratieff cycles,

- structural cycles of character and scope diversified in terms of time.

Each of these cycles exerts significant impact on the operations of container freight markets and their dynamics. Moreover, the markets are subject to the impact of global logistics system, which means that their mode of operation must be adapted to the requirements of global logistic supply chains management strategy. It is, therefore, an additional sub-system regulating the maritime container markets and another factor adding to its dynamics. Moreover, the markets operate in a close vicinity of other types of markets, i.e. commodity, monetary and labour markets which affect them significantly in subsequent cycles and stages of business cycle, maintaining its significant dynamics.

\section{Methodological aspects. The global maritime container market mechanism in times of crisis}

The global maritime container transport market is characterized, like no other freight market, by a very low level of fragmentation. Nowadays, its distinguishing feature involves strong integration of particular segments of these markets. It results, on the one hand, from high unification of this intermodal transport technology and its level of development on a global scale. On the other, from the increasing economic pressure, resulting from international competition, towards further concentration of entities and capital in this shipping segment. Consequently, it results in the increasing concentration of container flows in the geographical and spatial terms (WSC, 2018).

The supply side of maritime container markets attempts to react, relatively quickly from the perspective of this transport sector, to rapid changes on the demand side. Characteristically, despite high capital intensity of business activity conducted in this transport sector, it indicates rather high level of adaptation - however mainly of qualitative and structural nature, to the dynamic changes occurring on the demand side of these markets. However, due to the typically oligopolistic, competitive type of market, the supply side is definitely smaller in 
terms of quantity. It can be observed in the form of steady surplus of container fleet carrying capacity, i.e. its potential supply relative to the effective and potential demand (tonnage overcapacity).

It results from the fleet development strategy implemented by the carriers and perceived as the only instrument able to maintain the advantage within the competitive environment. Therefore, the market is unbalanced on a global scale and periodically, at significant decline in demand, becomes disrupted. Moreover, the strategy implemented in the conditions of limited use of price-based instrument (low level of demand and price elasticity) generates financial crisis among numerous carriers (low level of income and inability to exceed the breakeven-point), endangering their current accounting liquidity - threat of bankruptcy. The container market on the supply side is also characterised by significant entitywise integration processes - concentration of tonnage, capital and the market itself. The concentration involves:

- horizontal concentration, in the form of mergers and acquisitions as well as operational and production integration, i.e. establishing strategic and tactical shipping alliances at the main container shipping routes,

- vertical concentration, i.e. within the supply chain, e.g. investments of container owners into the container port terminals, their acquisitions, etc.

The demand side of global maritime container transport features significant dynamics of changes observed in time. As a result of definitely higher level of fluctuations of effective demand than potential supply of transport services on the container markets, the level of balance of these markets is low. Moreover, it is deteriorated by the lack of balance of commodity sequences at the majority of container routes. Consequently, as already mentioned, we can observe on these markets permanent state of imbalance - detachment of the demand side from the supply side. The state of serious imbalance - i.e. crisis existing in this mainly economically sensitive segment of global maritime shipping is reflected by the fluctuations in freight and charter rates. However, they reflect the existing state of imbalance only indirectly, mainly due to their relative rigidity (delayed reaction) regarding the dynamic changes in effective demand.

Their fluctuations in time reflect, in turn, the freight and charter indexes developed by brokerage houses as well as logistic forwards and operators. They are the only instrument for analysing these types of freight markets, and at the same time constitute grounds for multifaceted studies, i.e. evaluation of balance and imbalance of maritime container markets and forecasting changes related to effective demand versus potential supply. They are extremely important for practical reasons - mainly for ship owners, shippers, forwarders and logistic operators, as well as for the methodological and cognitive reasons.

The scale of fluctuations in the freight and charter rates is presented on the figures below. 

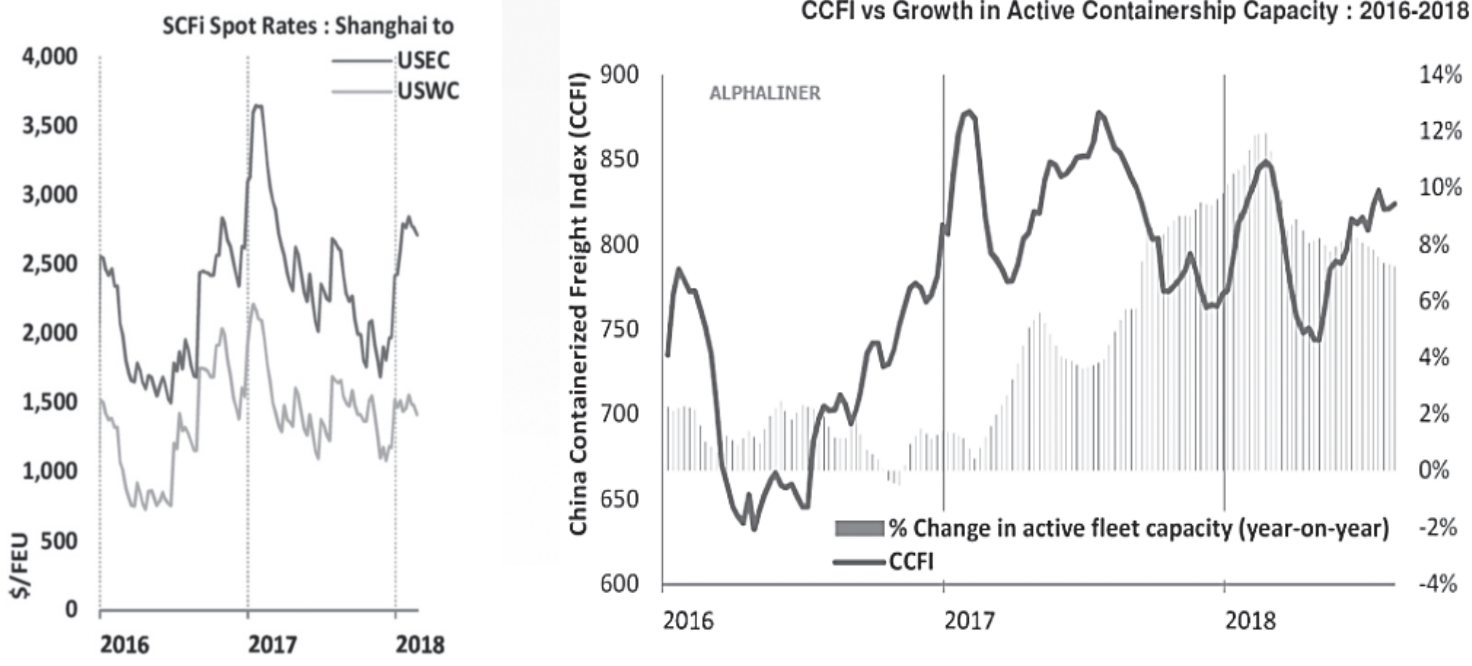

$\Delta$ Figure 4. Fluctuations of freight rates (USD/TEU) quoted at the main container routes in selected months between 2016-2018

Source: Alphaliner, 2018; UNCTAD, 2018. 
The fluctuations in demand for container operators' services and their results can be analysed with regard not only to the global maritime container market, but also to partial markets, i.e. their particular segments referring to the main container shipping routes on a global scale. Since this is where the phenomenon of unbalanced flow of goods within export - import relation, escalated by usually significant disturbance of transport, translates strongly into the demand side of the maritime container market, strongly emphasizing the phenomenon of asymmetry of transport within the main segments of global container market (UNCTAD, 2018). The asymmetry is featured not only by its direction-based aspect (eastbound - westbound), but also the aspect of quantity (tonnage). It strongly reflects the asymmetry in commodity exchange - within the global supply chains; the asymmetry which the container operators have to adapt to from the supply side, usually at significant expense (Grzelakowski, 2018). It results in the lack of effective use of the carrying potential of container operators rendering the related services and forced traffic of empty containers in trade. Their relatively high share in the total container turnover passed on these routes, statistically overstates the number of container circulation on a global scale, which directly affects the container load index (11.7 t/1 TEU) [2].

\section{Strategies of global maritime container operators during imbalance and crisis on the freight markets}

Maritime transport, due to its relatively high level of energy intensity, which can be observed in particular in the container shipping segment, strongly oriented to maintaining high standards of logistics and logistic concepts of the supply chain management on a global scale, can sense in a particular manner not only the results of market crisis - imbalance between the potential supply and effective demand, but also all consequences of fuel crisis. The crisis is usually reflected in the rapid increase in oil prices, which results in the increase in fuel, diesel oil and lubricants. They enhance the total global tonnage operating costs to a difficult-toaccept level relative to the level of income determined by variable level of freight and charter rates.

The container shipping fails to observe a clear positive correlation between the level of fuel prices and the level of freight rates. The increase in bunker prices is not in line, as indicated by the results of market analyses from the last fuel crisis of 2007/8, with the increase in freight rates (Benamara et al., 2012). It means that the mechanism of obtaining compensation for the increase in fuel prices and consequently in the overall tonnage operating costs through the increased income obtained as a result of growing freight rates in such situation in the maritime shipping, fails to operate. In such circumstances the container carriers must look for other means and forms of solving the problem (WSC, 2018). 
GLOBAL

CONTAINER

SHIPPING

Andrzej Grzelakowski

It is estimated that nowadays the bunker costs constitute on average over 40 per cent of total vessel operating costs, and in the case of container ships they are higher by even 20 per cent. Under the data of Germanischer Lloyd for an 8000 TEU vessel they amount to ca. 60 per cent of the vessel operating costs (Benamara et al., 2012). Therefore, in the case of significant increase in bunker costs, e.g. on a scale observed between 2007 and 2008, the ship owners had to take particular operational and tactical steps to meet the future operating challenges. Such actions resulted from the adopted strategies defining possible response and behaviour towards such crisis and involved, since it was impossible to increase the freight rates, the following:

- actions of short-term character,

- actions of medium- and long-term character.

The first ones, related mainly to the segment of liner shipping, involve in general:

- reduction in operational speed at all or some transport routes, namely the implementation of slow steaming strategy,

- reorganization of services to decrease the vessel operating costs,

- introduction of BAF - Bunker Adjustment Factor,

- tie-up of tonnage, as a form of temporary withdrawal from operation due to inability to cover high operating costs (Robinson, 2005).

The reduction in vessel speed leads to lower fuel consumption. In the container shipping segment the reduction in vessel speed by 10 per cent reduces fuel consumption on average by ca. 25 per cent (ICS, 2014). The result in the operating costs in such situation is significant and many operators choose such solution to survive during fuel crisis. However, it includes numerous drawbacks which in many cases make such approach even harmful for the ship owner due to the scale of indirect costs and economic and financial effects. Since the said strategy results in: 1/ not only prolonged time of voyage (travel) and consequently decrease in the number of performed production cycles of each vessel per year, and therefore, reduction in income from the sale of transport services, but also 2/ generation of additional often very high indirect costs resulting from the prolonged time of freezing the capital blocked in goods carried by sea and the increase in other logistic costs in the entire global land-maritime supply chain (Grzelakowski, 2016).

These costs resulting from the implementation of slow steaming strategy include also the costs which indirectly arise from excessive absorption of fixed capital by shipping operators, including mainly returned empties - mainly the containers. Their operating cycle in such conditions significantly extends the traditionally defined standards in this area. As a result - depending on the intensity of operational slow-down, where containers are transformed from unitised packaging to warehouses - there is significant growing demand for warehouses 
in the centres of production, distribution and consumption, which may lead - as it was observed during the latest crisis - to exhausting the reserves and lack of containers necessary for loading the goods (UNCTAD, 2018; ICS, 2018). The phenomenon generates not only additional transport and logistic costs, but also strong conflicts between the maritime carriers and shippers, which destabilize to some extent the existing forms of cooperation. The results of crisis situations occurring in one component of the supply chain transfer usually very quickly to other components distorting their operations and leading to onerous disruptions in the global supply chain.

The disruptions also occur when carriers, due to the increase in bunker prices, as it is happening these days (see Figure 6), introduce bunker surcharges (BAF)

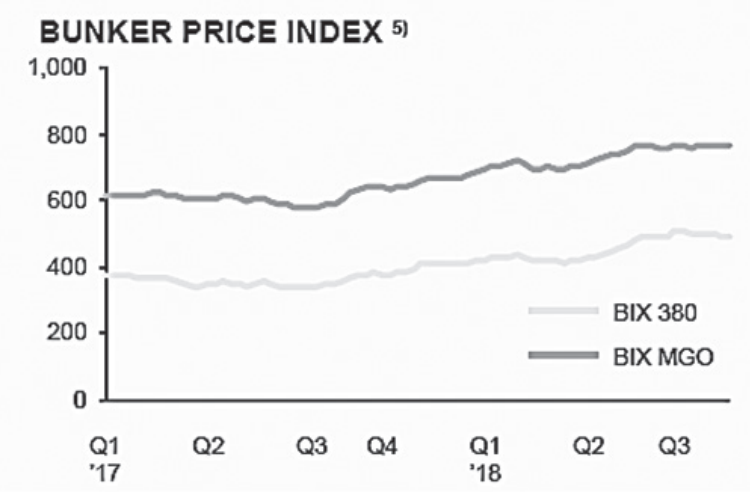

Average cost of ISO 380 bunker fuel across Shanghai, New York-New Jersey, and Rotterdam

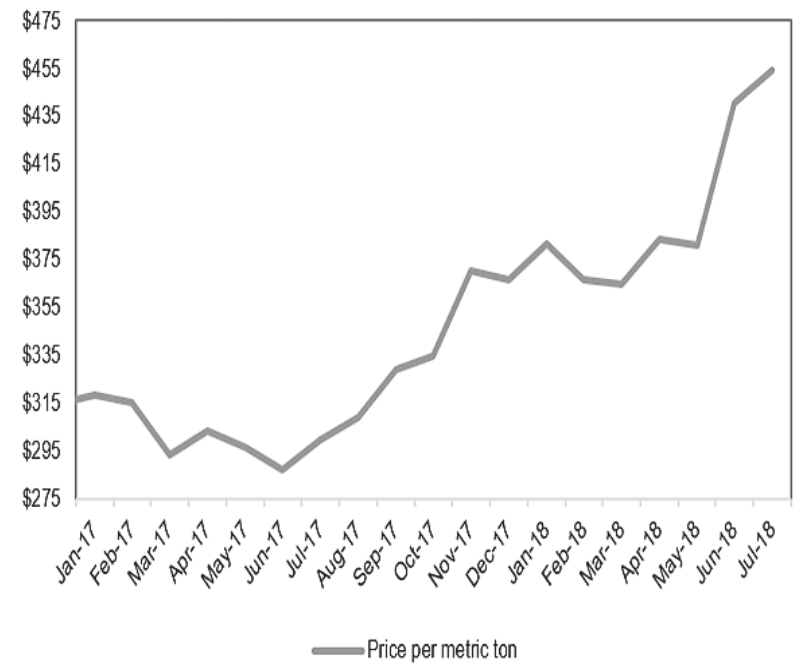

GLOBAL CONTAINER SHIPPING

Andrzej Grzelakowski
Figure 6. Bunker fuel prices and bunker price index in the recent two years

Source: Alphaliner, 2018; UNCTAD, 2018; ICS, 2018. 
GLOBAL CONTAINER SHIPPING

Andrzej Grzelakowski

which increase the costs of maritime transport, sometimes significantly and bearing in mind their best interests - reorganize the services. In both cases, these actions are always underpinned by the transfer of some costs generated by the fuel crisis to the consumers of transport services. If one of these short- and mediumterm strategies fails to bring the intended result, ship owners frequently try to apply also another, additional strategy from a wide range of possible solutions which strengthens (synergy) the basic strategy.

Being aware of possible long-term tendency regarding fuel price increase and consequently the increase in tonnage operating costs, ship owners look for other solutions related to their medium- and long-term development strategies including such crisis situations. They include:

- restructuring of tonnage which leads to the purchase of new, less energyintensive vessels, adjusted to the requirements of carriage routes,

- introduction of new, usually hybrid drive systems e.g. with elements of sail - SSS system (SkySails System) which made it possible on some routes to reduce the consumption of fuel even up to 50 per cent, which translated into the possibility to reduce fuel costs by 20 per cent,

- search for new carriage routes, in particular within ocean lines, allowing significant reduction of transport distance, time and costs,

- seasonal removal of vessels from operation (tied-up tonnage) with the intention to sell them on the second hand markets..

The presented shipping operators' strategies during fuel crisis are to a great extent complementary in their nature. However, the selection of a given strategy is rather difficult. It is conditional upon numerous factors dependent not only on the intensity of crisis and forecasts regarding the development of crisis situation, but also on the standing of a given ship owner on the commodity and freight markets. However, it is proven that mainly the standing on the market as well as competitive advantage are the fundamental elements which determine the ship owners' behaviour during crisis and the selection of relevant strategy.

\section{Discussion}

As a result of definitely lower than expected at the beginning of this decade growth rate of global effective demand for the services of maritime container operators and its significant fluctuations of seasonal and recurrent character, occurring when the container carriers seem unable to adapt (necessary reduction) the tonnage to these changes, this segment of global freight market has been in the state of creeping crisis since 2011. The crisis covers also other components of global logistic supply chains, destabilizing the relations existing in this sector.

The adjustment strategies of global container owners, implemented in the conditions of significant market imbalance are expressed mainly in the need to reduce unit costs of tonnage handling and the cost of carrying 1 TEU. The 
achievement of this goal involves: 1. introduction of mega container ships into operation (VLCC), 2. optimization of liner services by limiting their number, 3. limiting competition through actions leading to horizontal and vertical integration (mergers and acquisitions, establishing alliances, etc.), 4. expanding the scale of production and its diversification to minimize the threat of bankruptcy (capital engagement in other components of the supply chain). These actions lead to changing the business model of global container operators. The change is expressed in gradual departure from the confrontational model (model of total competition) towards a model based on cooperation within the formula of shipping alliance.

The strategies generate particular results for each component of the global supply chain where the container operators render their services. For ship operators they are expressed in: I. 1/ reduction of many components of operating costs - the result of cooperation and concentration of activities within alliances, 2. better adaptation of carrier, in the operational and financial aspect, to significant demand fluctuations on a given carriage route (decrease in competitive pressure and the related increase in nett income (EBITDA); as a result of such actions Maersk, COSCO and Hapag Lloyd recorded financial surplus in 2018. II. access of leading global container operators - Hapag Lloyd, CMA CGM, MOL and OOCL to NYSHEX Exchange (New York Shipping Exchange). The Exchange is famous for promoting digital forwarding contracts for the global container transport. Therefore, the solution promotes the largest forwarding companies. Thanks to the Exchange (NYSHEX), subsequent rounds of financing the ship owners' investments can be performed, and entering the Exchange in 2017 by two large ship owners, i.e. German Hapag-Lloyd and French CMA CGM, together with GE Ventures and Goldman Sachs funds additionally increased the opportunities to acquire financial resources for the development of maritime fleet. The effects for shippers and forwarders are perceived in a different light. Very fragmented market of shippers and forwarders is observing these changes with significant concern (growing concentration in the segment of container transport and unprecedented growth of market power of this component of supply chain), and are anxious about strong dictate of carriers and further reduction of the area of their operation, as well as possible reduction in the quality of services and lack of predictability of ship owners' behaviour within alliances. However, at the same time this component of supply chain can observe certain advantages: 1 . contracting within alliances and not with one carrier only, which gives possibilities of better risk management (better market transparency), 2 . alliances provide access to geographically larger logistic space than the one offered by individual operator, 3 . there is a greater possibility to organize subsequent shipments through the carrier since access to other vessels within a given alliance is ensured. 
GLOBAL CONTAINER SHIPPING

Andrzej Grzelakowski

The effects for ports and maritime terminals are perceived from the perspective of threats. The uncertainty and risk is increasing due to possible elimination of selected unattractive, from the perspective of alliance network of connections, container terminals and the concentration of ship services in megahubs (such as Zebrugge and Antwerp, declining importance of Algeciras, etc.). There is growing pressure on further port facilities regarding handling the alliance vessels and increase in handling capacity (ranking of ports and terminals), which refers to necessary increase in capital expenditure and search for new transport and logistic solutions (e.g. GRID Logistics). There is also possibility to prefer „own” ship owner's container terminal at the expense of other terminals, which may increase competition in this component of supply chain on a regional scale, leading to lower effectiveness of handling commodity flows in the global supply chain. The effects for economy and market regulators shall be perceived from numerous perspectives. On the one hand, the activities of global container operators lead to the reduction of seaborne carriage costs and consequently the logistic costs within the supply chains. It brings significant effects for the exporters and importers and final consumers of goods carried by sea. Moreover, the decline in maritime transport costs in the final prices of goods provides stimulus for the development of global trade and support of globalization processes and consequently, greater openness of markets. These activities also lead to the decrease in transport-intensity on a global scale, which results from rationalization of carriage in this segment of freight market. On the other hand, we can observe growing anxiety of countries, international organizations and freight market regulators (DG Competition and FMC) regarding the results of further concentration and elimination of competition (alliance is still a tolerated form of shipping cartel created by the post-conference era in regular shipping).

\section{Conclusion}

In conclusion, we can state that container alliances by preferring the consolidation of the shipping sector force changes not only in the previous model of container transport market operations, but also in the global supply chain. It refers to its particular components. The role of carrier is strengthened on an unparalleled scale compared to other entities. As a result, the carrier becomes a strong logistic operator market- and capital-wise. Consequently, we can observe the integration of markets and supply chains previously operating individually. We can also observe ,slimming down" of processes and operations as well as reduction of entities involved in the implementation of activities and objectives of the global logistic supply chain. However, it intensifies the concentration within the logistic chain, reducing the role of other components, in particular forwarders and land operators to the position of subcontractors performing the tasks of alliance or strong container operator. 
Such actions provide grounds for introducing innovative solutions in the sector of maritime logistics based on unified standard defined by regulators and shipping operators. The market behaviour of container owners resulting from their

strategy also strengthen the position of large global logistic operators, increasingly marginalizing the small and medium operators, which increase the competition in this segment of global logistic market.

\section{Notes}

[1] Supply data refer to total capacity of the container-carrying fleet, including multipurpose vessels and other types of vessels with some container-carrying capacity. Demand growth is based on million TEU lifts.

[2] It is estimated that $1 / 5$ of total container carried by sea on the global market is empty.

\section{Acknowledgments}

The publication of this paper has been financed from research project No. 463/DS/2018.

\section{References}

Alphaliner Weekly Newsletter (2018), Vol. 09, pp. 3-8.

Benamara, H., Hoffmann, J., Valentine, V., Fugara, H. (2012), "Fuel process, transport costs and the geography of trade", UNCTAD Transport Newsletter, Vol. 39 No. 39, pp. 7-8.

Branch, A.E. (2009), Global supply chain management and international logistics, Routledge. Taylor and Francis Group, New York and London.

Chopra, S., Meindl, P. (2010), Supply Chain Management. Strategy, Planning, and Operation, Fourth Edition, Pearson, New York.

Clarkson Research (2018), "Markets", Vol. 12, UK, China.

Global Insight (2016), "Insight \& Analysis", World Trade Service Brochure, No. 12.

Grzelakowski, A.S. (2012), „Globalizacja i jej wpływ na rozwój transportu morskiego i globalnych łańcuchów dostaw”, Prace i Materiały Instytutu Handlu Zagranicznego Uniwersytetu Gdańskiego, Gdańsk, No. 31.

Grzelakowski, A.S. (2014), "Container Shipping Operators as Integrators of Global Logistics Supply Chains”, Logistics and Transport, Vol. 21 No. 1.

ICS (2014), Shipping, world trade and the reduction of CO2 emission, United Nations framework convention on climate change (UNFCCC), London.

ICS (2017 and 2018), Annual review, ICS Publications, London.

ICS (2018), "Shipping industry urges European Commission to extend the Consortia Block Exemption Regulation”, ICS Newsletter, No. 12, pp. 2-7.

Mandryk, W. (2011), Measuring global seaborne trade, Lloyd's Marine Intelligence Unit. International Maritime Statistics Forum, New Orlean, pp. 29-34.

Mangan, J., Lalwani, Ch., Butcher, T. (2009), Global Logistics and Supply Chain Management, John Wiley \& Sons, New York. 
GLOBAL CONTAINER SHIPPING

Andrzej Grzelakowski
MDS (2018), Transmodal, Local \& Global Transport \& Logistics Research, London, UK. Pryke, S. (2009), Construction Supply Chain management: Concepts and Case Studies, Wiley-Blackwell, London.

Robinson, R. (2005), "Liner Shipping Strategy, Network Structuring and Competitive Advantage: A Chain Systems Perspective", in: Cullinane, K. (Ed.), Shipping Economics, Research in Transportation Economics, Vol. 12, Elsevier.

UNCTAD (2018), 2018 Review of maritime transport, UNCTAD secretariat, GenevaNY. WCS (2018), Global Ocean Trade, World Shipping Council Publications, London. 